University of Wollongong

Research Online

Faculty of Business - Papers (Archive)

Faculty of Business and Law

$1-1-2018$

Accommodating student diversity and different learning backgrounds

Ann M. Rogerson

University of Wollongong, annr@uow.edu.au

Louise C. Rossetto

University of Wollongong, celeste@uow.edu.au

Follow this and additional works at: https://ro.uow.edu.au/buspapers

Part of the Business Commons

Research Online is the open access institutional repository for the University of Wollongong. For further information contact the UOW Library: research-pubs@uow.edu.au 


\title{
Accommodating student diversity and different learning backgrounds
}

\author{
Abstract \\ Student mobility presents both challenges and opportunities in higher education due to language, cultural \\ and learning background differences among students. Effective integration of 'real world' group situations \\ into class and assessment activities assists students to develop skills in accommodating cross-cultural \\ language differences in line with convergent principles of communication accommodation theory. This \\ case study reports on a cross-cultural post-graduate Management subject in a regional Australian \\ university, demonstrating how explicit teaching results in improved learning outcomes by integrating \\ experiences with theory, while better preparing students to participate in a globalised workforce.

\section{Disciplines} \\ Business \\ Publication Details \\ Rogerson, A. M. \& Rossetto, L. Celeste. (2018). Accommodating student diversity and different learning \\ backgrounds. Journal of Intercultural Communication Research, Online First 1-10.
}




\title{
[FINAL DRAFT]
}

\section{Accommodating student diversity and different learning backgrounds}

\author{
Ann M. Rogerson ${ }^{\mathrm{a} *}$ and L. Celeste Rossetto ${ }^{\mathrm{b}}$ \\ ${ }^{a}$ School of Management, Operations and Marketing, Faculty of Business, University of \\ Wollongong, Wollongong, NSW, Australia; ${ }^{b}$ Learning, Teaching and Curriculum, \\ University of Wollongong, Wollongong, NSW, Australia
}

\section{Contact information:}

Dr. Ann M Rogerson*

Office 40.242, Faculty of Business

University of Wollongong

Northfields Avenue; Wollongong NSW 2522 Australia

Phone: +61 (2) 42215664

ORCID: 0000-0003-3864-9975

Twitter: @DrAnnMRogerson

LinkedIn: Dr Ann Rogerson

Email annr@uow.edu.au*

Dr. Celeste Rossetto

Office 11.208, Learning, Teaching \& Curriculum

University of Wollongong

Northfields Avenue; Wollongong NSW 2522 Australia

Phone: +61 (2) 42214103

ORCID: 0000-0001-6755-5965

Email celeste@uow.edu.au

\section{Disclosure statement:}

No potential conflict of interest is reported by the authors.

\section{Biographical notes:}

Ann M. Rogerson (D.B.A., MMgmt(Dist), MEd(HE)(Dist)) is a Senior Lecturer from the School of Management, Operations and Marketing, in the Faculty of Business at the University of Wollongong (UOW), Australia. Her research interests include interpersonal and intergroup workplace communication, leadership reflective practice, assessment design and academic integrity.

Celeste Rossetto (Ph.D., BA(Hons), Grad. Dip. Ed.(TESOL), RN) is a Senior Lecturer in Learning Development, Learning Teaching and Curriculum at the University of Wollongong (UOW), Australia. Her research interests include effective embedding of academic literacies for all students, transition points in higher education, doctoral writing and course reviews processes. 


\section{Accommodating student diversity and different learning backgrounds}

Student mobility presents both challenges and opportunities in higher education due to language, cultural and learning background differences among students. Effective integration of 'real world' group situations into class and assessment activities assists students to develop skills in accommodating cross-cultural language differences in line with convergent principles of communication accommodation theory. This case study reports on a cross-cultural post-graduate Management subject in a regional Australian university, demonstrating how explicit teaching results in improved learning outcomes by integrating experiences with theory, while better preparing students to participate in a globalised workforce.

Keywords: cross-cultural communication; heutagogy, communication accommodation theory; international students; assessment design

\section{Introduction}

One quarter of students in Australia's higher education sector are international with the majority of international students having a language background other than English (Norton \& Cakitaki, 2016). According to the Australian Government's Department of Education and Training (2017), 621,192 international students studied in Australian universities with almost one third coming from the People's Republic of China. Of these students, nearly two-thirds require English Language Intensive Courses for Overseas Students (ELICOS) as the first step to study at an Australian university (Department of Education and Training - Australia, 2015). International education activity is Australia's third largest export industry with an annual revenue of approximately \$US21.9 billion (Department of Education and Training - Australia, 2017).

While English is the language predominantly used in the Australian higher education sector, the Australian population is itself diverse in terms of Indigenous languages, other languages and cultures; the result of population growth through 
immigration rather than birth rates (Australian Treasury, 2010). More than one-fifth of Australia's permanent resident population speaks a language other than English at home (Australian Bureau of Statistics, 2017). The combination of student mobility and a diverse local population presents both challenges and opportunities in the higher education curriculum due to language, cultural and learning background differences within the student body. Embedding the application and integration of communication theory in learning experiences considers those challenges and takes advantage of the unique opportunities available for students to develop competencies in intercultural communication which are increasingly necessary in an era of globalisation.

International postgraduate students often arrive on or after the commencement date of their course. This is in part due to visa processes when it can take from 7 to 10 weeks and sometimes longer to complete formalities (Australian Government 2018). This transition from home country to Australia has multiple impacts. Firstly, students experience culture shock: finding accommodation, finding access to familiar food, and for many, living away from home for the first time in a foreign environment (Zhou, Jindal-Snape, Topping, \& Todman, 2008). This is compounded when students commence study, as their previous educational experiences have not always prepared them sufficiently for a Western education system that relies on interactions with lecturers, and staff, in addition to discussions in class, independent research for assignments and constructing arguments in English (Belford, 2017).

As part of a globalised educational experience, and to support international students in transitioning to their new institutions, it is important to establish situations where they are required to practise skills such as interpersonal and cross-cultural communication in a safe environment. Interpersonal communication focusses on interactions (Bambacas \& Patrickson, 2008), and in workplace situations, requires the 
construction and negotiation of meaning (Jian, Schmisseur, \& Fairhurst, 2008), and further, to the generation of understanding with and between employees (Hoon, 2007). Cross-cultural communication adds another dimension where language barriers (such as use of accents, terms and colloquialisms) can impact the effectiveness of interactions and outcomes (Harzing \& Feely, 2008; Herbert, Mockaitis, \& Zander, 2014). This is a particularly important skill for the development of global citizens. Cross-cultural communication difficulties also affect student interactions, particularly where students are required to cope with varieties of accented English (Chan \& Ryan, 2013). Consequently, it is critical to consider how strategies for accommodating language and cross-cultural communication differences can be embedded into educational experiences to benefit students during their course of study and better prepare them for workplace experiences.

This paper documents the collaborative teaching practice of the authors who were not only concerned with what students learned but how they learned and how this could be supported to develop their interpersonal communication skills while building student confidence and knowledge in their new learning environments. We present and discuss the successful outcomes achieved in developing, embedding and integrating cross-cultural communication skills through discipline-specific scaffolded activities in group-work assessments and tutorial exercises in a post-graduate subject: Managing People in Multinational Organisations. The subject promotes the importance of effective communication across differences in language and cultural backgrounds in workplace contexts in an international business masters level program.

During a review of the subject prompted by a change in teaching periods, it was recognised that the assessment tasks in previous instances assessed theory and application but did not provide opportunities to develop and practise cross-cultural 
communication skills, nor accommodate or effectively acknowledge differences in prior educational experiences. Class introductions identified that most students had previously studied in their mother tongue and their education to date did not encourage independent learning. Discussions with students revealed that the majority were familiar with traditional assessment tasks of essays and examinations where there was little emphasis on in-text citation, independent research, academic reading, critical analysis and reflective thinking and writing (Andrade, 2006). While some students achieved the stated subject outcomes and most were passing the subject, a deeper level of learning was possible, incorporating cross-cultural interactions, in addition to English language practice and academic skill development. There is a need to embed English speaking experiences into curricula, as many overseas English language programs focus predominantly on written English for academic study (Sawir, 2005). To facilitate the desired changes, an approach that linked communication theory to an educational theoretical approach was most likely to achieve the deeper learning required for students to succeed in their studies, while achieving the learning outcomes and enhance future employment opportunities.

\section{Theoretical Approaches}

Communication accommodation theory (CAT) (Giles, 1980, 2016) was selected as the communication theory to frame the cross-cultural communication scenarios to prepare students for future employment in globalised workforces where differences in cultural and language background are the norm. CAT examines adjustment (or accommodation) strategies used (or not used) during interactions such as conversations and evaluates the "social consequences of those adjustments" (Dragojevic, Gasiorek, \& Giles, 2016, p.36). Convergence refers to the adjustment of communication behaviours to adapt to differences between an individual and others by using certain words, 
changing the pace of speech, or adopting accents as conversational tactics (Gallois, Ogay, \& Giles, 2005). Accommodating actual or perceived individual differences assists in achieving effective communication outcomes (Adams, 2005), which in a globalised business environment leads to enhanced organisational outcomes (Zhang, Tsui, Song, Li, \& Jia, 2008).

As a complementary educational theory, heutagogy was selected as an educational approach where learning is self-determined and integrated with experiences and theory (Hase \& Kenyon, 2007). Described as a form of self-determined learning, heutagogy progresses adult learning to become an integrative process related to contexts and situations. This approach transcends the acquisition of knowledge and skills by embedding a level of deeper cognitive learning in experiences which can be later applied to familiar and unfamiliar situations (Hase \& Kenyon, 2007; Kenyon \& Hase, 2001). For heutagogical approaches to be successful, consideration of each student's level of existing study skills, motivation and capacity for self-reflection is required (Canning \& Callan, 2010). Consequently, the authors (as a subject coordinator working closely with an academic language and learning (ALL) specialist) determined that assessment tasks and tutorial activities could be redesigned to incorporate cross-cultural communication elements with academic skill development. By analysing the performance of students in previous sessions, we identified the interpersonal communication and academic skills students would need to complete assessment tasks successfully, not just to pass, but also to learn and to experience a different type of learning than they had previously encountered.

\section{Assessments, activities and tutorial redesign}

The heutagogical educational approach informed the design of the new assessment tasks and activities. Group-work assessments, tutorial activities, and 
reflective elements were redesigned to practise and promote the convergent principles of CAT where interactants adapt their communication to achieve mutual understanding and successful outcomes. An example of the learning outcomes and a related assessment task is provided in Appendix 1. The student group allocations were purposely diverse in terms of linguistic and cultural backgrounds where the only language of commonality was English. This placed students in situations where they had to accommodate language and cultural differences using English to successfully complete activities and assessment tasks. Each activity was explicitly linked to the next to build students' academic capacities while requiring the students to interact in oral exchanges and compare writing approaches.

Activities also offered opportunities for students to learn together through collaborative exercises where they had to communicate orally with each other in groups, and seek clarifications from the subject coordinator (as facilitator) in order to resolve issues raised collectively by the group. The new assessment tasks required students to address problems with no concrete answers, thus requiring a cognitive approach to collaborative problem solving (Lasker \& Weiss, 2003). Through observing discussions and interactions, the subject coordinator also identified when students were experiencing difficulties during discussions and carefully intervened to explain points of confusion to develop common understanding of terms and approaches and refocus the group on the activities and tasks.

A series of tutorial activities were designed to address particular assessment tasks in the subject so that students' learning was scaffolded. Scaffolded tasks had individual and group elements that were introduced to develop and extend research, writing and reflection skills to link to CAT. Embedding academic literacy skills into the curricula have been shown to be more successful at developing skills compared to 
stand-alone programs (Haggis, 2006; McKay \& Devlin, 2014; Murray, 2013) particularly when combined with a heutagogical approach to academic skill development (McWilliams \& Allan, 2014)

For example, one series of tutorial exercises were created for students to independently analyse key elements of journal articles, before bringing their individual annotations together to construct a combined group literature review. These exercises are provided as Appendix 2. Students pooled disparate pieces of literature from the individual written contributions into a cohesive, coherent and meaningful extended writing assessment within a restrictive word limit. In tutorials, the group work was facilitated providing opportunities for the subject coordinator to observe, clarify, support and evaluate group interactions and activities.

To further communication convergent skill development, other tutorials examined survey preparation. Groups of students with mixed language backgrounds were required to discuss and together prepare an integrated summary methodology paper. Discussion required students who were ESL speakers to develop their listening and speaking skills to enhance these macro-skills in English, while developing the native English speaking students' skills in the nuances of accented English. This required students to apply convergent conversational communication strategies by adjusting pace, tone and word selection to achieve a deeper level of understanding with their group members.

Later tasks developed reflection skills, leading to a final individual report assignment where students were required to reflect on what they had learned from their cross-cultural communication experiences. Students were able to recognise and articulate the difficulties they encountered and the accommodation strategies they used to overcome communication barriers. Written reflections revealed that students could 
identify what approaches they used to overcome differences in language, opinion and writing styles, to evaluate the success or limitation of their communication accommodation strategies and tactics and how they might apply in future contexts inside and outside educational situations.

\section{Other skill development relevant to globalised workplaces}

Students were given explicit teaching around group formation and supported by proformas which gave them the necessary framework to develop as a functioning team while accommodating different language backgrounds. It enabled them to experience how and why effective cross-cultural communication is crucial for success in a multinational team environment (in this case delivering assessable work). Observations and group comments were later unpacked in tutorial discussions to link back to CAT and real-world cross-cultural employee interactions. It also provided students with an actual record of what they did and how they progressed during the trimester as a group. All these resources provided a flexible model for students to refine their cross-cultural communication approaches relevant to future situations and contexts.

It became apparent through observations and feedback that many students did not have academic research skills, so they were given explicit teaching around searching for, accessing and then evaluating the literature they had selected. Our students were unused to reading academic journals in English and so needed scaffolded support to understand the structure of journals to guide their expectations. It was necessary for students to improve their academic vocabulary and to learn how to analyse critically and then, to communicate this to their peers in the form of three individual annotated bibliographies. This allowed students to create a combined literature review for the group report. In this way, they could apply what they had learned together in writing while practising English speaking and listening skills. The second assessment task 
extended their learning as students were asked to reflect and compare cross-cultural communication differences they encountered in their group, as this would affect their ways of working and communicating when in employment, especially as students need to understand how business is conducted at the global level (Randolph, 2011). Students were also exposed to examples of poor and better reflections and how to construct their own reflections which subsequently aligned them to their immediate and future learning.

\section{Discussion}

The students' results and reflective insights indicated that the outcomes exceeded expectations in demonstrating what they had learned about effectively working by accommodating cross-cultural communication differences, and how it could apply to their future workplaces. Students engaged with the activities, gained confidence in asking clarification questions, and demonstrated a deeper level of individual learning aligning with the heutagogical educational approach. Further feedback received from students after the session was completed highlighted their increased confidence in finding they could apply their new knowledge of academic skills across other subjects and coping with cross-cultural language backgrounds in situations inside and outside the university.

The intentional allocation of students to cross-cultural communication groups ensured that they could not revert to their mother tongue which while unsettling, provided a contextual example allowing them to experience (and apply) some convergent principles of CAT. The subject coordinator explained that few employees have control over work-based placements and that this subject provided an opportunity to experience and understand what it was like to enter a new work environment where individuals had a diversity of language, cultural and educational backgrounds. The 
achievement of a level of convergence in the cross-cultural team interactions embedded the deeper cognitive learning through experience which is part of the heutagogical approach to learning. Contextual approaches help students connect management content to life contexts particularly in the development of English speaking skills (Ampa, Muhammad Basri, \& Andriani, 2013), and as a critical element of post-graduate learning experiences, enables students to test these skills in a safe environment ( $\mathrm{Wu}$, Griffiths, Wisker, Waller, \& Illes, 2001).

While the subject coordinator created the necessary safe environment for students (Kolb \& Kolb, 2005) to question, comment and explore not only the subject matter, she became less central to the learning process and morphed into a facilitator of learning (Hase and Kenyon 2007). Students experienced a transition from their previous teacher-centred learning to an independent self-determined learning context (Canning, 2010). Independent learning based on heutagogical principles better prepares students for their future outside of supportive educational environments while embracing learning as a life-long practise (Blaschke, 2012).

\section{Conclusion}

This paper contributes to the advancement of the integration and application of communication theory to the teaching and learning environment for international students by embedding a global perspective in a postgraduate coursework subject. Through scaffolded activities and assessments, students experience deeper learning about interpersonal and cross-cultural communication in a simulated 'real-life' context. By providing cross-cultural communication experiences prior to explaining the theoretical concepts underpinning the subject content, students are better able to connect their learning experiences to communication theory for later application in familiar and unfamiliar situations. By developing multiple communication opportunities, both oral 
and written, to encourage confidence and build knowledge, students gain sufficient skills to participate effectively when employed in a globalized workforce.

Learning experiences designed and facilitated in this subject develop individual competencies to accommodate differences and nuances in language, offering a richer understanding of the importance of accommodating differences in cultural, national and learning backgrounds. The reflection tasks and later feedback demonstrated that students had learned to accommodate the language and cross-cultural differences they encountered, indicating their unacknowledged capacity for achieving communication convergence. Subsequent student feedback confirmed that the lessons learned in the facilitated cross-cultural group communication experiences extended beyond the subject, providing confidence in both their improved communication and academic skill development. In offering students interpersonal communication experiences as part of their institutional learning, they establish the capability to develop their own strategies that enhance their capacity to perform as global citizens regardless of the country in which they work. As educators, we have seen how students benefit from developing international perspectives in the communication curriculum through the integration of communication theory. 


\section{References:}

Adams, S. M. (2005). Positive affect and feedback-giving behavior. Journal of Managerial Psychology, 20(1), pp. 24-42.

Ampa, A. T., Muhammad Basri, D., \& Andriani, A. A. (2013). The development of contextual learning materials for the English speaking skills. International Journal of Education and Research, 1(9), pp. 1-10.

Andrade, M. S. (2006). International students in English-speaking universities: Adjustment factors. Journal of Research in International education, 5(2), pp. 131-154.

Australian Bureau of Statistics. (2017). Census of Population and Housing: Australia Revealed, 2016. Canberra: Australian Government Retrieved from http://www.abs.gov.au/ausstats/abs@.nsf/Latestproducts/2024.0Main\%20Featur es22016?opendocument \&tabname $=$ Summary \&prodno $=2024.0 \&$ issue $=2016 \& n u$ $\underline{m}=\&$ view $=$.

Australian Treasury. (2010). Intergenerational Report 2010 Australia to 2050: future challenges. Canberra: Australian Government Retrieved from http://archive.treasury.gov.au/igr/igr2010/report/pdf/IGR_2010.pdf.

Bambacas, M., \& Patrickson, M. (2008). Interpersonal communication skills that enhance organisational commitment. Journal of Communication Management, 12(1), pp. 51-72. doi:10.1108/13632540810854235

Belford, N. (2017). International students from Melbourne describing their crosscultural transitions experiences: Culture shock, social interaction, and friendship development. Journal of International Students, 7(3), pp. 499-521.

Blaschke, L. M. (2012). Heutagogy and Lifelong Learning: A Review of Heutagogical Practice and Self-Determined Learning. International Review of Research in Open and Distance Learning, 13(1), pp. 56-71.

Canning, N. (2010). Playing with heutagogy: Exploring strategies to empower mature learners in higher education. Journal of Further and Higher Education, 34(1), pp. 59-71. doi:10.1080/03098770903477102

Canning, N., \& Callan, S. (2010). Heutagogy: spirals of reflection to empower learners in higher education. Reflective Practice, 11(1), pp. 71-82. doi:10.1080/14623940903500069

Chan, H. T., \& Ryan, S. (2013). Challenging stereotypes: International accounting students in Australia. Journal of Modern Accounting and Auditing, 9(2), p 169.

Department of Education and Training - Australia. (2015). Study pathways of international students in Australia. Canberra: Australian Government Retrieved from https://internationaleducation.gov.au/research/researchpapers/Documents/Study\%20Pathways\%202015_2.pdf.

Department of Education and Training - Australia. (2017). Export income to Australia from international education activity in 2016-17. Canberra: Australian Government Retrieved from https://internationaleducation.gov.au/research/ResearchSnapshots/Documents/Export\%20Income\%20FY2016\%E2\%80\%9317.pdf.

Dragojevic, M., Gasiorek, J., \& Giles, H. (2016). Accommodative strategies as core of the theory. In H. Giles (Ed.), Communication accommodation theory: Negotiating personal relationships and social identities across contexts (pp. 3659). Cambridge: Cambridge University Press. 
Gallois, C., Ogay, T., \& Giles, H. (2005). Communication accommodation theory: A look back and a look ahead. In W. B. Gudykunst (Ed.), Theorizing about intercultural communication (pp. 121-148). Thousand Oaks: Sage.

Giles, H. (1980). Accommodation theory: Some new directions. In S. de Silva (Ed.), Aspects of Linguistic Behaviour (Vol. 9, pp. 105-136). York: University Press.

Giles, H. (2016). Communication accommodation theory: Negotiating personal relationships and social identities across contexts Cambridge, UK: Cambridge University Press.

Haggis, T. (2006). Pedagogies for diversity: Retaining critical challenge amidst fears of 'dumbing down'. [Article]. Studies in Higher Education, 31(5), pp. 521-535.

Harzing, A. W., \& Feely, A. J. (2008). The language barrier and its implications for HQ-subsidiary relationships. Cross Cultural Management: An International Journal, 15(1), pp. 49-61. doi:10.1108/13527600810848827

Hase, S., \& Kenyon, C. (2007). Heutagogy: A child of complexity theory. Complicity: An International Journal of Complexity and Education, 4(1), pp. 111-118.

Herbert, K., Mockaitis, A. I., \& Zander, L. (2014). An opportunity for east and west to share leadership: A multicultural analysis of shared leadership preferences in global teams. Asian Business \& Management, 13(3), pp. 257-282. doi:http://dx.doi.org/10.1057/abm.2014.10

Hoon, C. (2007). Committees as strategic practice: The role of strategic conversation in a public administration. Human Relations, 60(6), pp. 921-952. doi:10.1177/0018726707080081

Jian, G., Schmisseur, A., \& Fairhurst, G. T. (2008). Organizational discourse and communication: The progeny of Proteus. Discourse \& Communication, 2(3), pp. 299-320. doi:10.1177/1750481308091912

Kenyon, C., \& Hase, S. (2001) Moving from Andragogy to Heutagogy in Vocational Education. Paper presented at the Research to Reality:Putting VET Research to Work, Adelaide. http://www.avertra.org.au/PAPERS\%202001/kenyon\%hase.pdf

Kolb, A. Y., \& Kolb, D. A. (2005). Learning styles and learning spaces: Enhancing experiential learning in higher education. Academy of Management Learning \& Education, 4(2), pp. 193-212.

Lasker, R. D., \& Weiss, E. S. (2003). Broadening participation in community problem solving: A multidisciplinary model to support collaborative practice and research. Journal of Urban Health, 80(1), pp. 14-47. doi:10.1093/jurban/jtg014

McKay, J., \& Devlin, M. (2014). 'Uni has a different language... to the real world': Demystifying academic culture and discourse for students from low socioeconomic backgrounds. Higher Education Research \& Development, 33(5), pp. 949-961.

McWilliams, R., \& Allan, Q. (2014). Embedding academic literacy skills: Towards a best practice model. Journal of University Teaching and Learning Practice, 11(3), pp. 1-20.

Murray, N. (2013). Widening participation and English language proficiency: A convergence with implications for assessment practices in higher education. Studies in Higher Education, 38(2), pp. 299-311. doi:10.1080/03075079.2011.580838

Norton, A., \& Cakitaki, B. (2016). Mapping Australian higher education 2016. Australia: G. Institute. https://grattan.edu.au/wp-content/uploads/2016/08/875Mapping-Australian-Higher-Education-2016.pdf 
Randolph, W. A. (2011). Developing global business capabilities in MBA students. Journal of Management Inquiry, 20(3), pp. 223-240. doi:10.1177/1056492611401027

Sawir, E. (2005). Language difficulties of international students in Australia: The effects of prior learning experience. International Education Journal, 6(5), pp. 567-580.

Wu, S., Griffiths, S., Wisker, G., Waller, S., \& Illes, K. (2001). The learning experience of postgraduate students: Matching methods to aims. Innovations in Education and Training International, 38(3), pp. 292-308.

Zhang, A. Y., Tsui, A. S., Song, L. J., Li, C., \& Jia, L. (2008). How do I trust thee? The employee-organization relationship, supervisory support, and middle manager trust in the organization. Human Resource Management, 47(1), pp. 111-132.

Zhou, Y., Jindal-Snape, D., Topping, K., \& Todman, J. (2008). Theoretical models of culture shock and adaptation in international students in higher education. Studies in Higher Education, 33(1), pp. 63-75. doi:10.1080/03075070701794833 


\section{Appendix 1: Subject learning outcomes and sample assessment task}

\section{Subject Student Learning Outcomes}

(1) Demonstrate cross-cultural knowledge and interpersonal skills to manage and work with Individual teams and organisations in a variety of cultural and global contexts.

(2) Apply analytical, critical and communications skills to understand predict and manage people ethically and professionally in different organisational and cultural contexts.

\section{Assignment/Assessment task: Group Report}

Selected Topic Trimester 3: Collectivism and Individualism Differences between Students

- Note: the topic for this assessment task is changed from session to session to support rigour and academic integrity requirements

\section{Assessment Requirements:}

(1) Students are required to work in groups. Each group should comprise 4-5 students of different cultural and language backgrounds

(2) Each member must select different academic journal readings from fellow members. Journals cannot be selected from the subject prescribed readings. This encourages research skills and conversation within the group.

(3) Each group member is required to construct three (3) annotated bibliographies based on their selected articles. Reference sources must be correctly presented in Harvard format. Each annotated bibliography should be no longer than 250 words (excluding the reference source details).

(4) Each group member will then write $3 \times 250$ words annotated bibliographies for inclusion in the group report. A group constructed literature summary of the group annotated bibliographies (1000 words). The methodology or writing up how the study (class survey) was conducted (300-500 words)

Weighting: 20\%. Part of the mark was allocated to individual bibliographies (60\%) with the balance $(40 \%)$ allocated to the group. 


\section{Appendix 2: Tutorial activity related to sample assessment task}

\section{Tutorial Activity: Writing Individual annotated bibliographies}

\section{Notes to Lecturer/Tutor}

There are valuable signposts in academic texts such as journal articles and books. At first, the plethora of information residing on databases can overwhelm students when they are used to dealing just with textbooks or business journals and reports. This activity is designed to give students some practical tips when they conduct their necessary research without spending hours searching for relevant information and also, writing their thoughts up into coherent texts. Note: This is a good initial activity where the students are asked to read a particular paper prior to class and then work on it in class.

Step 1: (1 minute) Ask students to use the article they have already read and brought to class

Step 2: (15 minutes) Ask students to use the matrix (Table 1) to begin the process and then respond to the questions.

Step 3: (15minutes) Ask students to compose an annotation for their assessment task. 
Table 1: Annotated Bibliography Matrix

\begin{tabular}{|c|c|}
\hline Article 1 & \\
\hline Bibliographic deta & \\
\hline Main argument & \\
\hline $\begin{array}{l}\text { Methodology } \\
\text { (How was the text } \\
\text { written? How was } \\
\text { the information } \\
\text { showcased?) }\end{array}$ & \\
\hline $\begin{array}{l}\text { What are the } \\
\text { arguments in this } \\
\text { article? } \\
\text { (So what does it } \\
\text { mean? } \\
\text { Why is it so } \\
\text { important?) }\end{array}$ & $\begin{array}{l}\text { Defines ... } \\
\text { Explains ... } \\
\text { Themes ... }\end{array}$ \\
\hline & Importance... \\
\hline $\begin{array}{l}\text { Usefulness for } \\
\text { your annotated } \\
\text { bibliography / } \\
\text { literature review }\end{array}$ & $\begin{array}{l}\text { 1... It defines/ argues/describes/analyses... } \\
2 \ldots \text { It purported to/criticises/disputes... }\end{array}$ \\
\hline & 3... It disregards/asserts/recommends... \\
\hline
\end{tabular}


Activity 1: Writing Individual annotated bibliographies (Step 2 in Tutorial notes)

1. Does the title of this article give you any clues about its content?

2. What is/are the argument/s in this article?

3. What evidence do the authors offer to support their claims?

4. Write a couple of sentences to summarise the article in your own words.

Activity 2: Writing a draft annotated response (Step 3 in Tutorial notes)

Please write a coherent and cohesive response to the article in 250 words.

Follow-up activity to map the 12-15 entries to determine difference and commonalities in the literature.

Activity 3: Grouping Literature into themes

What other themes can you use? Think about things like - study population, study type, methodology. Use the table below and add further columns for extra headings as decided by your group.

Table 2: Grouping literature into themes

\begin{tabular}{|l|l|l|l|}
\hline Key themes & Theory used & Country researched & Related references \\
\hline & & & \\
\hline & & & \\
\hline
\end{tabular}

